\title{
Frequency of Borrelia in Morphea Lesion by Polymerase Chain Reaction in Northeast of Iran
}

\author{
Mohhamad Javad Yazdanpanah ${ }^{1}$; Norieh Sharifi ${ }^{2}$; Alireza Khooei $^{2}$; Mahnaz Banihashemi ${ }^{1}$; \\ Mohammad Khaje-Daluee ${ }^{3}$; Azadeh Shamsi ${ }^{4}$; Kiarash Ghazvini ${ }^{5, "}$ \\ ${ }^{1}$ Department of Dermatology, Research Center for Skin Diseases and Cutaneous Leishmaniasis, Ghaem Hospital, Mashhad University of Medical Sciences, Mashhad, IR Iran \\ 2 Department of Pathology, Mashhad University of Medical Sciences, Mashhad, IR Iran \\ 3 Department of Social Medicine, Mashhad University of Medical Sciences, Mashhad, IR Iran \\ 4 Psychiatry and Behavioral Sciences Research Center, Ibn-e-Sina Hospital, Mashhad University of Medical Sciences, Mashhad, IR Iran \\ 5 Antimicrobial Resistance Research Center, Department of Microbiology and Virology, Mashhad University of Medical Sciences, Mashhad, IR Iran \\ ${ }^{*}$ Corresponding author: Kiarash Ghazvini, Antimicrobial Resistance Research Center, Department of Microbiology and Virology, Mashhad University of Medical Sciences, Mashhad, \\ IR Iran. Tel: +98-5118012589; +98-9151248938, Fax:+98-5118409612, E-mail: Ghazvinik@mums.ac.ir
}

Received: April 26, 2014; Revised: August 19, 2014; Accepted: August 27, 2014

Background: The etiology of morphea is still unknown. Borrelia spp. as a causative agent of morphea has been discussed since 1985, but the relationship remains uncertain.

Objectives: We aimed to find the frequency of Borrelia in morphea lesions by polymerase chain reaction(PCR) in northeast of Iran.

Patients and Methods: Sixty six patients with morphea were prospectively included in the present study. For each patient, formalin-fixed, paraffin-embedded tissue blocks of skin lesion biopsies were examined for Borrelia spp. DNA using PCR.

Results: No Borrelia DNA was detected by PCR in skin lesions of patients with morphea.

Conclusions: The result of this study showed no relationship between Borrelia infection and morphea lesions and in other word indicated

that morphea, at least in Iran, is not caused by Borrelia spp.

Keywords: Morphea; Polymerase Chain Reaction; Borrelia spp.

\section{Background}

Although many etiological agents such as trauma, vaccination, radiotherapy, hormonal factors and infections have been proposed for morphea (localized scleroder$\mathrm{ma}$ ), the main causative agent is still unknown. In 1985, spirochaetal etiology was suggested for morphea (1). This hypothesis drew great attention as it necessitated antibacterial treatment for morphea. In the following years, serological, immunohistochemical and culture approaches were performed to determine the role of Borrelia burgdorferi in the pathogenesis of morphea (2-5). However, these studies concerning the relation between $B$. burgdorferi and morphea have had conflicting results. In recent years, several authors have used polymerase chain reaction (PCR) to detect B. burgdorferi in skin lesions of patients with morphea, but the relationship between morphea and this organism has still remained controversial (6-10). The most acceptable reason for this confliction is the possible geographical variations and different Borrelia subspecies which affect the relationship, as Borrelia has frequently been detected in European and Asian patients, but not in cases from the USA or Scotland (10-13).

\section{Objectives}

The present study was designed to record the occur- rence of $B$. burgdorferi among skin biopsies of patients with morphea. It was the first study in our country. If the link is firmed, the next studies can focus on the role of antibiotic therapy in morphea.

\section{Patients and Methods}

This was a case series study performed on skin biopsy specimens of patients with clinical and pathological diagnoses of morphea. By reviewing the records of the Pathology Department of Imam Reza and Ghaem hospitals as the two main university hospitals in northeast of Iran during October 2003 to October 2009, all the patients with histological compatibility with morphea were selected. Sixty six patients with morphea were prospectively included in the present study. After reconfirmation of histological diagnosis, five to eight sections (5 $\mu \mathrm{m})$ were cut from each formalin-fixed, paraffin-embedded (FFPE) tissue block and were deparaffinized by adding xylene (Sigma-Aldrich, LLC). Thereafter, DNA was extracted from those tissue samples using commercial DNA isolation kit for FFPE (QIAamp DNA FFPE Tissue Kit; Qiagen $\mathrm{GmbH}$, Hilden, Germany) according to the manufacturer's instructions (QIAamp DNA FFPE Tissue Procedure).

The quality of the DNA sample and the absence of PCR

Copyright (C) 2015, Ahvaz Jundishapur University of Medical Sciences. This is an open-access article distributed under the terms of the Creative Commons Attribution-NonCommercial 4.0 International License (http://creativecommons.org/licenses/by-nc/4.0/) which permits copy and redistribute the material just in noncommercial usages, provided the original work is properly cited. 
inhibitors were checked in all the samples by amplification of a part of the human b-actin gene. Afterwards, the presence of Borrelia DNA was tested by PCR in a Techne gradient thermal cycler (TC-5000 gradient thermal cycler, Techne, UK). This study was performed by a PCR kit (GenePak DNA PCR test, Isogene Lab Ltd. Russia) which could detect three species of Borrelia (B. burgdorferi, B. garini, B. afzelii) (14).

Five microliters of each DNA sample was added using a hot-start technique. The amplification condition comprised an initial denaturation step of two minutes at $95^{\circ} \mathrm{C}$ and then 43 cycles as one minute at $95^{\circ} \mathrm{C}, 50$ seconds at $58^{\circ} \mathrm{C}$, and one minute at $72^{\circ} \mathrm{C}$, with the final extension step prolonged to two minutes at $72^{\circ} \mathrm{C}$ to ensure complete amplification of the target. Positive and negative controls were included in each batch of amplifications. Electrophoresis in 1\% agarose gel (Sigma-Aldrich Co. LLC. Germany) was used for the analysis of the PCR products. PCR products were visualized by ethidium bromide (ETBr) staining under UV light. Visualizing the 445-bp fragment was interpreted as positive result. Precautions to avoid cross-contamination were taken in every assay (15).

\section{Results}

The patients consisted of 40 females (60.6\%) and 26 males (39.4\%), with a mean age of $28.39 \pm 17.28$ years. The youngest patient in this study was one and the oldest was 76 years old at the diagnosis time. The mean duration from the onset of lesions to the time of biopsy was $15.5 \pm 23.86$ months. In 26 patients (39.4\%), the lesions had appeared during the last six months, indicating an active process. Biopsies were taken mainly from the trunk $(n=38,57.6 \%)$ and lower extremities ( $\mathrm{n}=14,21.2 \%) ; 7$ (10.6\%) were from the upper extremities and 7 (10.6\%) from the head and neck area. The lesions were more frequent on the trunk (abdomen, $\mathrm{n}=6$; back, $\mathrm{n}=18$; chest, $\mathrm{n}=10$; flank, $\mathrm{n}=4$ ), than leg $(n=14), \operatorname{arm}(n=7)$, head (forehead, $n=4$; scalp, $n$ $=2$ ) and neck $(n=1)$. The results are shown in Table 1 .

According to the classification of Peterson, the clinical manifestations of morphea were of the plaque type in 59 (89.4\%), linear in 6 (7.6\%) and frontoparietal morphea in 2 (3\%) patients (16). Results are shown in Table 2.

Isolation of sufficient DNA with regard to quality and quantity was shown in all the clinical specimens by successful amplification of a part of the human b-actin gene. No Borrelia DNA was detected in skin biopsies of 66 patients with morphea with PCR(Figure 1).

Table 1. Lesion Localization in Patients With Morphea According to Gender ${ }^{a}$

\begin{tabular}{lcc}
\hline Lesion Localization & Female & Male \\
\hline Trunk & $25(62.5)$ & $13(50)$ \\
Lower extremities & $6(15)$ & $8(30.8)$ \\
Upper extremities & $4(10)$ & $3(11.5)$ \\
Head and neck & $5(12.5)$ & $2(7.7)$ \\
\hline
\end{tabular}

${ }^{\mathrm{a}}$ Data are presented as No.(\%).

\begin{tabular}{lcc}
\multicolumn{3}{l}{ Table 2. Clinical Manifestations of Morphea According to Gender } \\
\hline Clinical Manifestations & Female & Male \\
\hline Plaque morphea & $39(97.5)$ & $20(76.9)$ \\
Linear morphea & $0(0)$ & $5(19.2)$ \\
Frontoparietal morphea & $1(2.5)$ & $1(3.8)$ \\
\hline
\end{tabular}

${ }^{\mathrm{a}}$ Data are presented as No.(\%).

Figure 1. Results of Polymerase Chain Reaction

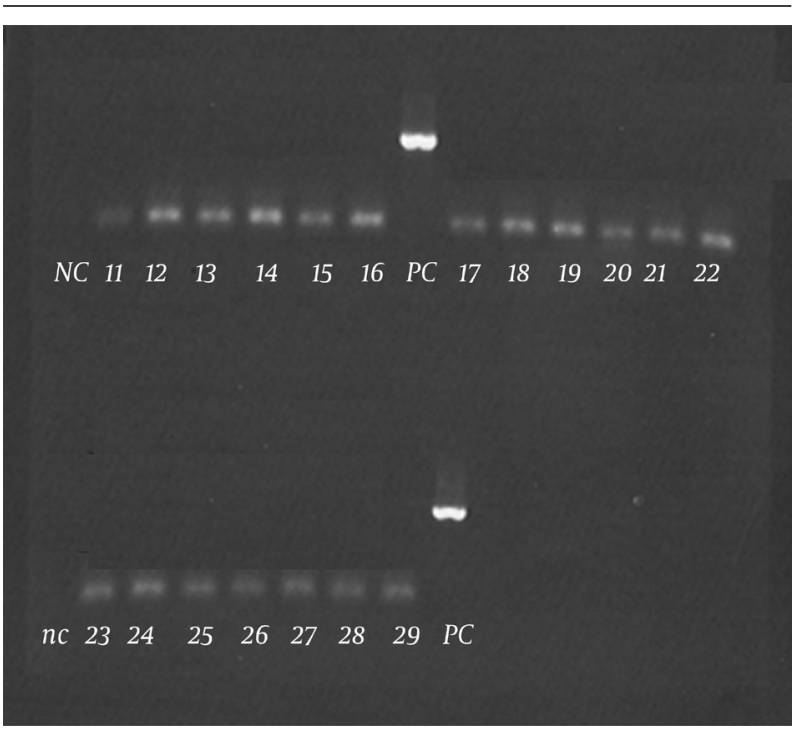

The lanes show the PCR products. NC, negative control; PC, positive control; Samples 11 To 29 are negative.

\section{Discussion}

The present study was designed to determine the frequency of Borrelia spp. in morphea lesion in our region and showed no relationship between Borrelia infection and development of morphea. PCR was performed in 66 cases with confirmed morphea to detect Borrelia DNA in skin biopsies. All the 66 cases were negative for Borreliaspecific DNA, despite successful amplification of appropriate positive controls in every test, demonstrating the lack of evidence for an association between Borrelia infection and morphea. In reviewing other studies, initial studies used serological methods for investigation the correlation between Borrelia infection and morphea. In several studies, all the tested patients with morphea were seronegative, while some other studies found specific antibodies against Borrelia in 6 - 54\% of unselected patients with morphea (2, 5-8, 17-26). Since negative serology does not exclude previous infection with Borrelia and positive serology may merely represent coincidental infection, other studies sought more definite evidence of a causal link by seeking to demonstrate the organism in biopsies of skin lesions taken from patients with morphea.

Attempts to visualize Borrelia-infected organisms directly in histological sections after appropriate staining 
have demonstrated spirochaetes in only a small number of cases (2, 3, 19-21, 23, 27, 28). Several studies using culture of Borrelia from biopsies of morpheic lesions have shown completely negative results $(2,17,18,25,27)$, while in a small number of cases positive results have been achieved $(4,20,22,23,28)$. In view of these conflicting results, recent studies have focused on PCR techniques to demonstrate the organism. Once more the results have been contradictory. Studies reporting a positive association between Borrelia infection and morphea have shown evidence of the organism in $26-100 \%$ of cases $(8,10,26$, $29,30)$, whereas in further 10 reports including our current one, no positive case has been identified (5, 7, 9, 11-13, $18,25)$. Isolated studies have reported a positive association in countries such as Italy, Switzerland, Puerto Rico, Turkey, and Japan, and negative association in Spain, Finland, Holland, the USA, some parts of Germany and France $(2,3,10,18,25-27,29,30)$.

All the PCR examinations were thoroughly controlled by the use of positive and negative controls. Based on these procedures, there is a high probability that we would have been able to detect Borrelia DNA, had it been present. Fujiwara and coworkers suggested that morphea might be caused by certain subspecies of B. burgdorferi which are endemic, exclusively in certain geographical areas (10). Since the literature suggests that there is a strong geographical relation between Borrelia infection and morphea, the results of the present study, which was the first study concerning the association between infection with Borrelia spp. and morphea in northeast of Iran, suggests that morphea is probably not associated with Borrelia spp. in northeast of Iran. These results indicate that in northeast of Iran, there is no association between infection with Borrelia spp. and the subsequent development of morphea. This could explain why all patients do not benefit from antibiotic therapy. The reason for the inconsistent results in studies using PCR could be the low number of microorganisms found in the tissue, ie, below the detection threshold for this technique (5-7, 11, $25,31)$. Other explanations include previous antibiotic treatment, old stage of the disease, wrong biopsy site (eg, from the negative sclerotic area), or wrong fixation of tissue specimens leading to DNA cross-linking (e.g. with inadequately buffered formalin). In this study, we used FFPE tissue blocks, so the abovementioned points could have caused some limitations in our study.

In conclusion, PCR examination showed no evidence for Borrelia infection in our group of patients with morphea. Therefore, we found consistent evidence for absence of $B$. burgdorferi infection in patients with morphea in northeast of Iran. The result of this study showed no relationship between Borrelia infection and morphea lesions and in other word indicated that morphea, at least in Iran, is not caused by Borrelia spp. This study proposed a geographical relationship between different Borrelia subspecies as causative agents of morphea, which was absent in our region. If the link is firmed, the next studies can focus on the role of antibiotic therapy in morphea.

\section{Acknowledgements}

The authors wish to thank the Deputy of Research Affairs of Mashhad University of Medical Sciences for providing financial support for this research and also Ethics Committee of Mashhad University of Medical Sciences for review and approval (Grant No. 87517). We also thank Ms Heravi for her excellent technical performance.

\section{Authors' Contributions}

Study concept and design: Mohhamad Javad Yazdanpanah, Alireza Khooei, Mohammad Khaje-Daluee, Azadeh Shamsi, Kiarash Ghazvini. Analysis and interpretation of data: Mohhamad Javad Yazdanpanah, Norieh Sharifi, Alireza Khooei, Mahnaz Banihashemi, Mohammad Khaje-Daluee, Azadeh Shamsi, Kiarash Ghazvini. Drafting of the manuscript: Mohhamad Javad Yazdanpanah, Alireza Khooei, Mahnaz Banihashemi, Mohammad Khaje-Daluee, Azadeh Shamsi, Kiarash Ghazvini. Critical revision of the manuscript for important intellectual content: Mohhamad Javad Yazdanpanah, Norieh Sharifi, Alireza Khooei, Mahnaz Banihashemi, Mohammad Khaje-Daluee, Azadeh Shamsi, Kiarash Ghazvini. Statistical analysis: Mohhamad Javad Yazdanpanah, Mohammad KhajeDaluee, Kiarash Ghazvini.

\section{Funding/Support}

This study was funded by Mashhad University of Medical Sciences.

\section{References}

1. Aberer E, Neumann R, Stanek G. Is localised scleroderma a Borrelia infection? Lancet. 1985;326(8449):278

2. Raguin G, Boisnic S, Souteyrand P, Baranton G, Piette JC, Godeau P, et al. No evidence for a spirochaetal origin of localized scleroderma. Br J Dermatol.1992;127(3):218-20.

3. Ross SA, Sanchez JL, Taboas JO. Spirochetal forms in the dermal lesions of morphea and lichen sclerosus et atrophicus. Am J Dermatopathol.1990;12(4):357-62.

4. Weber K, Preac-Mursic V, Reimers CD. Spirochetes isolated from two patients with morphea. Infection. 1988;16(1):25-6.

5. Weide B, Schittek B, Klyscz T, Schuz K, Stark M, Rassner G, et al Morphoea is neither associated with features of Borrelia burgdorferi infection, nor is this agent detectable in lesional skin by polymerase chain reaction. Br J Dermatol. 2000;143(4):780-5.

6. Ranki A, Aavik E, Peterson P, Schauman K, Nurmilaakso P. Successful amplification of DNA specific for Finnish Borrelia burgdorferi isolates in erythema chronicum migrans but not in circumscribed scleroderma lesions. J Invest Dermatol. 1994;102(3):339-45

7. Wienecke R, Schlupen EM, Zochling N, Neubert U, Meurer M, Volkenandt M. No evidence for Borrelia burgdorferi-specific DNA in lesions of localized scleroderma. J Invest Dermatol.1995;104(1):23-6.

8. Schempp C, Bocklage H, Lange R, Kolmel HW, Orfanos CE, Gollnick H. Further evidence for Borrelia burgdorferi infection in morphea and lichen sclerosus et atrophicus confirmed by DNA amplification. J Invest Dermatol.1993;100(5):717-20.

9. De Vito JR, Merogi AJ, Vo T, Boh EE, Fung HK, Freeman SM, et al. Role of Borrelia burgdorferi in the pathogenesis of morphea/ 
scleroderma and lichen sclerosus et atrophicus: a PCR study of thirty-five cases.J Cutan Pathol.1996;23(4):350-8.

10. Fujiwara H, Fujiwara K, Hashimoto K, Mehregan AH, Schaumburg-Lever $\mathrm{G}$, Lange $\mathrm{R}$, et al. Detection of Borrelia burgdorferi DNA (B garinii or B afzelii) in morphea and lichen sclerosus et atrophicus tissues of German and Japanese but not of US patients. Arch Dermatol. 1997;133(1):41-4.

11. Dillon WI, Saed GM, Fivenson DP. Borrelia burgdorferi DNA is undetectable by polymerase chain reaction in skin lesions of morphea, scleroderma, or lichen sclerosus et atrophicus of patients from North America. J Am Acad Dermatol. 1995;33(4):617-20.

12. Fan W, Leonardi CL, Penneys NS. Absence of Borrelia burgdorferi in patients with localized scleroderma (morphea).J Am Acad Dermatol. 1995;33(4):682-4.

13. Colome-Grimmer MI, Payne DA, Tyring SK, Sanchez RL. Borrelia burgdorferi DNA and Borrelia hermsii DNA are not associated with morphea or lichen sclerosus et atrophicus in the southwestern United States. Arch Dermatol. 1997;133(9):1174.

14. Vynograd N, Komarenko N. Molecular-genetic typing of Borrelia circulating in Kyiv Oblast. Ann Acad Med Siles. 2013;67(6):380-3.

15. Kwok S, Higuchi R. Avoiding false positives with PCR. Nature 1989;339(6221):237-8.

16. Peterson LS, Nelson AM, Su WPD, editors. Classification of morphea (localized scleroderma).; Mayo Clinic Proceedings.; 1995; Elsevier; pp. 1068-76.

17. Lupoli S, Cutler SJ, Stephens CO, Wright DJ, Black CM. Lyme disease and localized scleroderma-no evidence for a common aetiology. BrJ Rheumatol. 1991;30(2):154-6.

18. Meis JF, Koopman R, van Bergen B, Pool G, Melchers W. No evidence for a relation between Borrelia burgdorferi infection and old lesions of localized scleroderma (morphea). Arch Dermatol. 1993;129(3):386-7.

19. Daoud MS, Su WP, Leiferman KM, Perniciaro C. Bullous morphea: clinical, pathologic, and immunopathologic evaluation of thirteen cases. J Am Acad Dermatol. 1994;30(6):937-43.

20. Aberer E, Stanek G, Ertl M, Neumann R. Evidence for spirochetal origin of circumscribed scleroderma (morphea). Acta Derm Venereol.1987;67(3):225-31.

21. Aberer E, Kollegger H, Kristoferitsch W, Stanek G. Neuroborreliosis in morphea and lichen sclerosus et atrophicus.J Am Acad Dermatol.1988;19(5 Pt1):820-5.

22. Aberer E, Klade H, Stanek G, Gebhart W. Borrelia burgdorferi and different types of morphea. Dermatologica. 1991;182(3):145-54.

23. Aberer E, Stanek G. Histological evidence for spirochetal origin of morphea and lichen sclerosus et atrophicans. Am J Dermatopathol.1987;9(5):374-9.

24. Breier P, Klade H, Stanek G, Poitschek C, Kirnbauer R, Dorda W, et al. Lymphoproliferative responses to Borrelia burgdorferi in circumscribed scleroderma. BrJ Dermatol.1996;134(2):285-91.

25. Alonso-Llamazares J, Persing DH, Anda P, Gibson LE, Rutledge BJ, Iglesias L. No evidence for Borrelia burgdorferi infection in lesions of morphea and lichen sclerosus et atrophicus in Spain. A prospective study and literature review. Acta Derm Venereol. 1997;77(4):299-304

26. Trevisan G, Stinco G, Nobile C, Bonin S, Stanta G. Detection of Borrelia burgdorferi in skin biopsies from patients with morphea by polymerase chain reaction.J Eur Acad Dermatol Venereol. 1996;6(1):15-9.

27. Aberer E, Kersten A, Klade H, Poitschek C, Jurecka W. Heterogeneity of Borrelia burgdorferi in the skin. Am J Dermatopathol. 1996;18(6):571-9.

28. Breier FH, Aberer E, Stanek G, Khanakaha G, Schlick A, Tappeiner G. Isolation of Borrelia afzelii from circumscribed scleroderma. BrJDermatol. 1999;140(5):925-30.

29. Eisendle K, Grabner T, Zelger B. Morphoea: a manifestation of infection with Borrelia species? Br J Dermatol. 2007;157(6):1189-98.

30. Ozkan S, Atabey N, Fetil E, Erkizan V, Gunes AT. Evidence for Borrelia burgdorferi in morphea and lichen sclerosus. IntJ Dermatol. 2000;39(4):278-83.

31. Goodlad JR, Davidson MM, Gordon P, Billington R, Ho-Yen DO Morphoea and Borrelia burgdorferi: results from the Scottish Highlands in the context of the world literature. Mol Pathol. 2002;55(6):374-8. 